\title{
Sustainable Strategies for Promoting the Horezu Pottery and the Cultural Landscape of Horezu, Romania
}

\author{
Smaranda Maria Bica, Elena Roxana Florescu*
}

Faculty of Architecture, Polytechnic University of Timisoara, Romania

Copyright $\bigcirc 2017$ by authors, all rights reserved. Authors agree that this article remains permanently open access under the terms of the Creative Commons Attribution License 4.0 International License

\begin{abstract}
Romania occupies on the UNESCO list of Immaterial Cultural Patrimony only four positions. Since December 2012 the Horezu pottery entered this short list. This pottery is presented in most of the handicraft stores all over the country, but otherwise lacks any other promotion policies: information, data about the geographical position and the beautiful hilly landscape, history of the handicraft and data about the former and contemporary artists, presentation of the variety of decoration motifs, local gastronomy traditions etc. Today tourists have come to visit the 17 th-century Monastery, shortly stop to see the pottery in display on the access road and eventually acquire some products. The visibility of the valuable production of Horezu is minor, but a greater influx of tourist in the present conditions would be unsustainable. The paper intends to outline some directions for a sustainable promotion of the pottery itself, but also of the varied valuable traditions, of the architectural dowry, of the natural attractions and of other riches existing in the area.
\end{abstract}

Keywords Sustainable Development, Cultural Landscape, Handicraft, Tradition, Ecotourism

\section{Introduction}

Horezu pottery is a traditional craft, still kept in northern Valcea county, at the foot of the Carpathian mountains. The craft was included in the UNESCO Immaterial Heritage List as it reflects the local identity and knowledge of potters from Horezu, kept from generation to generation, thus preserving techniques and specific motifs that give it a unique character.

However, the craft is in danger due to the reduced opportunities in the rural areas of supporting this occupation financially, thereby reducing the number of craftsmen. Like all rural areas in Romania, Horezu faces the migration of the population towards towns and cities.
A survey ${ }^{i}$ was undertaken by this research team in order to study the national recognition of UNESCO's Immaterial Heritage status, as well as other important aspects concerning the Horezu Microregion. Results responses show that less than $30 \%$ of Romanians know that the pottery craft was included in the list of Immaterial Heritage and, about the importance of the craft, $18.3 \%$ of respondents said they did not know more details. Also, other features of the Horezu Microregion are not acknowledged among the local community and nationwide. Just $17.6 \%$ of respondents said they had visited the area given that fact that 2 UNESCO objectives out of the 10 ranked in Romania are located there. Therefore, the entire cultural heritage should be acknowledged in order to create sustainable strategies for the development of the area and to sustain the invaluable pottery craft.

\subsection{The Pottery Craft in Horezu Microregion - Maintaining a Valuable Tradition}

Authentic artisans in the area still use traditional materials and techniques. In the village of Olari (which means "potters"), where most of the craftsmen are located, visitors are invited to find out and experience the process that lies behind creating pottery, and also the origins and the characteristics of the decoration.

Currently, there are around 50 local potters, meeting within the Potters Association of Horezu which helps maintain an authentic core by promoting quality ceramics. According to the survey conducted in this study, among those who own a piece of pottery Horezu, 63.8\% said that they purchased it from craft stores, $12,5 \%$ from local craftsmen and $23,7 \%$ by ordering on the internet. Just a little percentage of visitors or buyers had a direct contact with the local craftsmen, which clearly shows that the object is more recognized than the actual handicraft that has to be preserved, undermining its cultural importance.

Given the higher media coverage, the ceramics trade flourished in the last years, but the consequences are not 
necessarily encouraging. The lack of sufficient information for the buyers, instead of protecting the UNESCO status, allowed the development of opportunistic initiatives under the title of Horezu pottery, producing and producing low-quality objects. As a result, more and more objects appeared on the market, addressed to unsuspecting buyers representing pottery produced in other locations, even in other countries.

The packages in which the ceramics are sold provide little or no information on what is actually important about the craft, do not provide suitable images or present the history of the handicraft, where the actual craftsmen are and how they produce the objects. Along the access road, pottery is sold in improvised shops that do not present a suitable image of the craft. These aspects have a negative impact on the number of potters still practicing in Horezu, as their work is not fully appreciated and the authentic products are less promoted, being replaced by cheaper, mass produced objects.

\section{The Evolution, Techniques and Specific Motifs of the Handicraft}

The Romanian pottery has a long history, having its roots in the prehistoric time and later developed by the Thracian Dacian with influences from the ceramics of the Greeks and Romans. The Horezu pottery fits into the overall Romanian ceramic but has a very specific style.

In the eighteenth century, the Horezu pottery adapts from a more practical endeavor towards art and luxury, having its highlight in the reign of Constantin Brancoveanu, founder of the Horezu Monastery, ruler of the Southern Principate of Wallachia between 1688 -1714. After establishing the School of Art at the Horezu Monastery, the Brancoveanu art style flourished by developing its vocabulary by adding to the local tradition elements of the Renaissance through the Ottoman Empire branch. The Brancoveanu Art Style shows an original Romanian character enriched with foreign influences. It is visible in architecture, local traditions and crafts that are perfectly adapted to the natural environment. Therefore, the pottery craft continues to be a correspondence between the values embodied by the built heritage - The Monastery of Horezu, and those of the Immaterial Heritage. This is noticeable by the coherence that is found both at the conceptual level of the entire object - be it artistic or actual construction work, but also at the level of compositional processes and motifs.

The techniques of creating the Horezu pottery remained the unchanged until now. A specific sequence of operations and instruments are similar to all craftsmen: a mixer for cleaning the earth, a potter's wheel and comb for shaping, a hollowed-out bull's horn stick for decoration, and a wood burning stove for firing. The paints used are natural and the colors vary from bright shades of brown, red, green, blue to the so-called "Horezu ivory" for the background of the vessels.

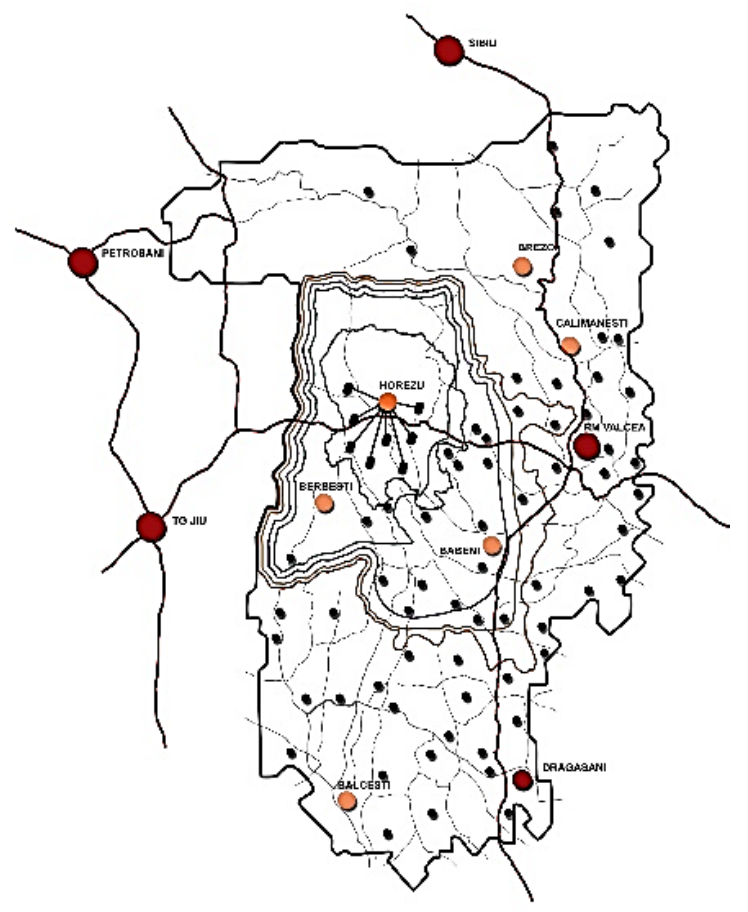

Figure 1. Map showing the location of Horezu

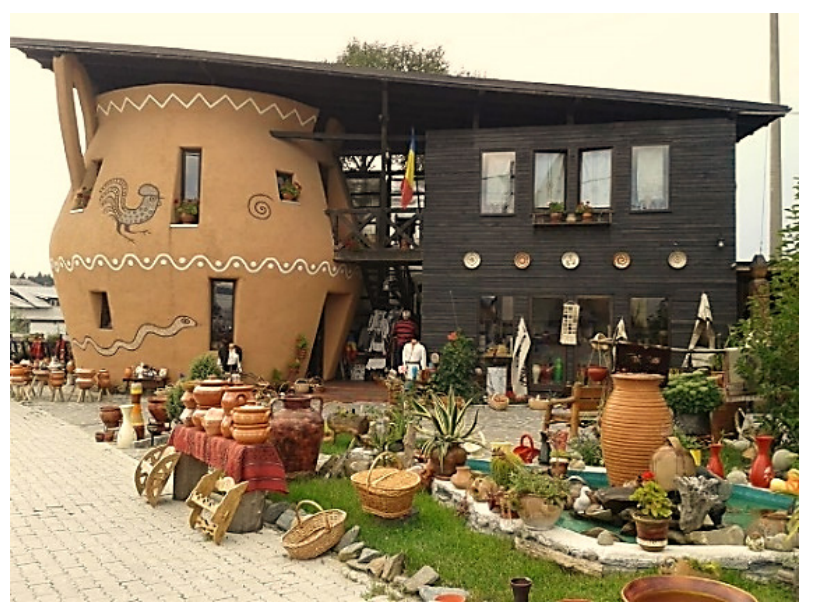

Figure 2. How the pottery is presented Region and its area of influence and sold in local shops

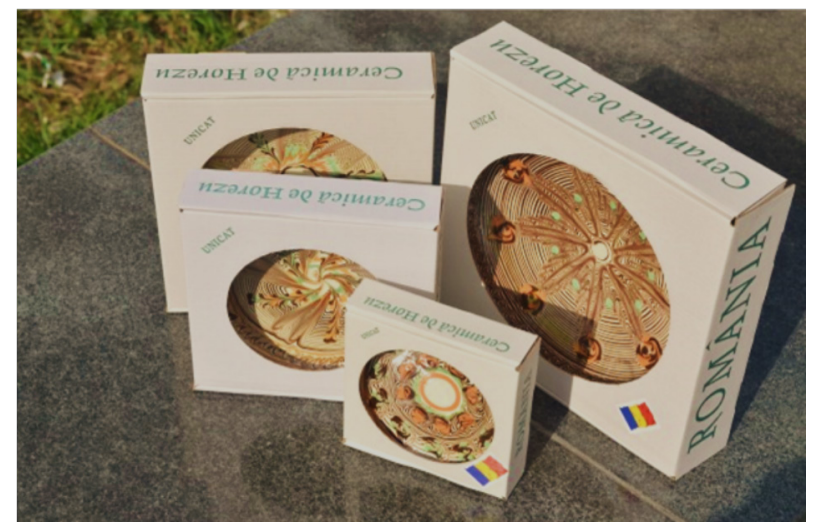

Figure 3. How the pottery is presented Region and its area of influence and sold in local shops 
The Horezu pottery decoration combines traditional motifs with later oriental influences resulting in unique ornamental compositions. The decorative friezes are made through the alternative use of a variety of motifs. Abstract geometrical ornaments are used - points and spirals, freely drawn or in combined patterns using the local process of "jiravare" (decoration technique made by leaking the colors on the edges of the vessels towards the center, using a pointed instrument called "gaita"). Cosmomorphic ornaments like the sun and the star are two images that organized the radial layout of the ceramics - spirals, twists and circles being representations of the solar symbol. Floral motifs: rosebuds, wheat ears, zoomorphic elements: birds, snakes, as well as anthropomorphic elements or scenes, are inspired from the rural settings.

Many of the symbols do not maintain a connection with the initial source of traditional inspiration, but they are kept from generation to generation. The best-known motif, "Cocosul de Horezu" ( the Horezu Rooster), detached its meaning from the original symbol of rebirth but remained in the collective consciousness as the emblem of a traditional and authentic lifestyle.

\section{Local Initiatives and Sustainable Proposals for Promoting the Horezu Cultural Landscape}

The Horezu Microregion is a territory with a population of about 33,200 inhabitants. The studied area is part of a homogeneous geographical unit, known as "Oltenia de sub Munte" (Oltenia under the mountain). A microsystem can be identified, grouping a set of villages with strong historical, economical and socio-cultural connections in which interventions can be optimized for an efficient exploitation of the natural resources in the area.

The attempt to update the Horezu rural setting, far from representing a nostalgic attitude, can be considered as a sustainable solution in terms of urbanism and conservation of the cultural landscape in the economic and social disruption following the 1990 change of political regime. By detecting the essence of the traditional traits, one can rephrase the rural social life and offer the option of shaping specific identities that match the requirements of local, regional conflicting tendencies thus expressing and highlighting important cultural elements.

The cultural landscape is a set of traits, characteristics, and forms of an area which provide a specific interpretation of the following elements: physical forms, natural and anthropic systems, built environment. Only through raising awareness and promoting these elements, supported by appropriate local economic development policies, the area can be regenerated and better living conditions can be provided for the residents.

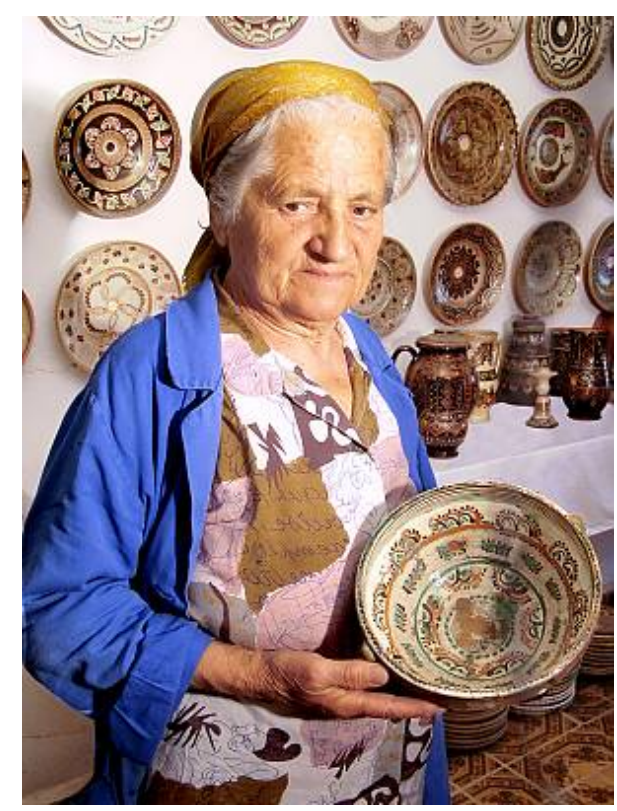

Figure 4. Traditional potter

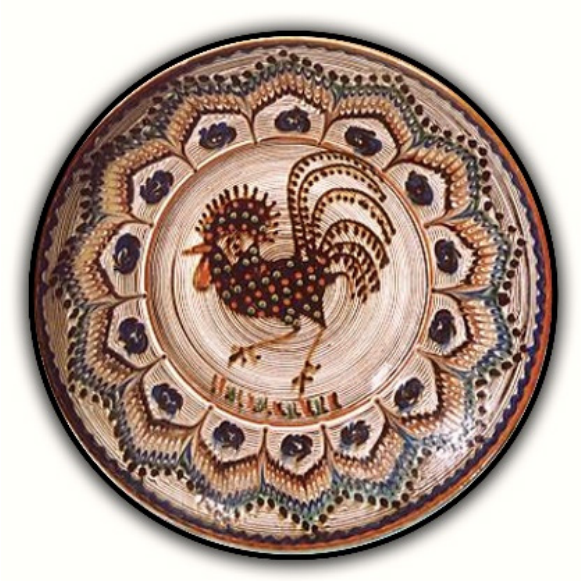

Figure 5. Traditional plates with the Horezu Rooster and the star, Eufrosina Vicsoreanu the decorations are made using the process of "jiravare"

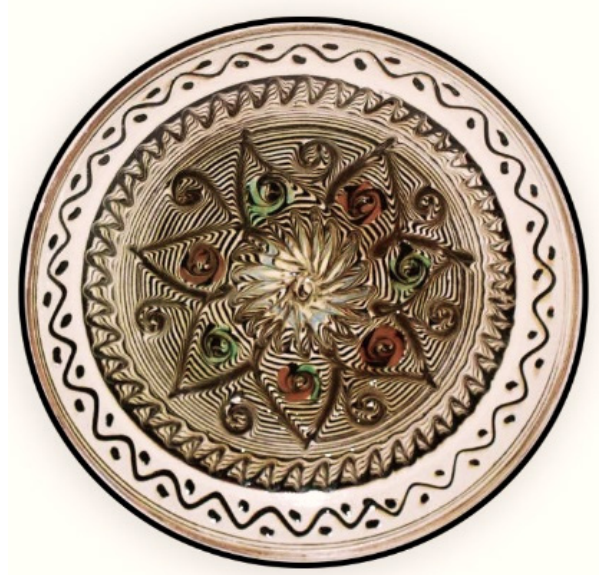

Figure 6. Traditional plates with the Horezu Rooster and the star, Eufrosina Vicsoreanu the decorations are made using the process of "jiravare" 


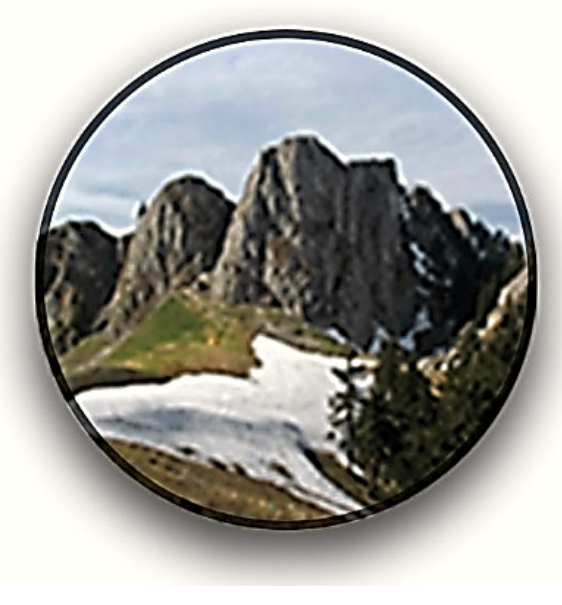

Figure 7. Buila Vanturarita

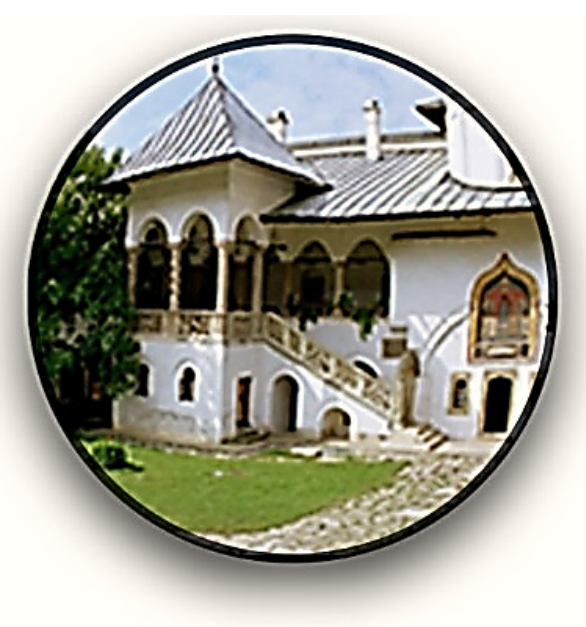

Figure 8. The Horezu Monastery

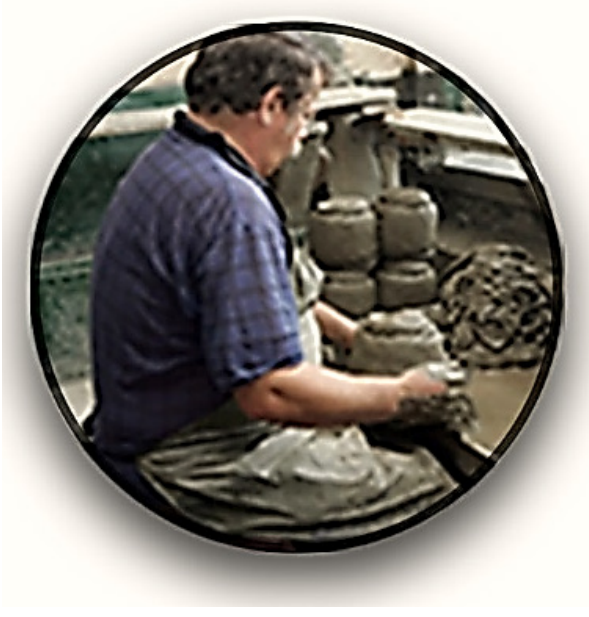

Figure 9. Potter in his workshop

\subsection{Promoting the Horezu Pottery}

In order to sustainably promote the Horezu pottery, several measures are required that aim to protect the authentic image and the craft itself. First, it is important to conceive a coherent brand that will provide sufficient information to costumers on the character of the craft and its importance. This can take place through information campaigns or through craft fairs where traditional artisans can exhibit their work and share their craftsmanship.

The first attempt to create a local brand initiated in 2015, at the "Cocosul de Horezu" Ceramics Fair by introducing the title "Horezu - where the earth takes shape". This event was attended by the General Assembly of the European Territorial Cooperation of Ceramic Cities, politicians, and local artisans. This meeting was conducted in order to connect Romanian potters with their counterparts in other European countries in order to find together workable solutions to ensure the permanence of this craft, affected by the loss of important centers of the competition with cheaper industrial products.

To get the desired results, information campaigns need to be interdisciplinary, addressing varied audiences through interactive activities which may include workshops and lectures on ceramics and the Microregion of Horezu while offering full touristic packages that include all the local attractions.

Pottery workshops are constantly organized in the local information center mainly addressed to tourists, as well as in the "Constantin Brancoveanu" High school and the "Children's Club", having a target group more than 2500 youngsters from the Horezu region.

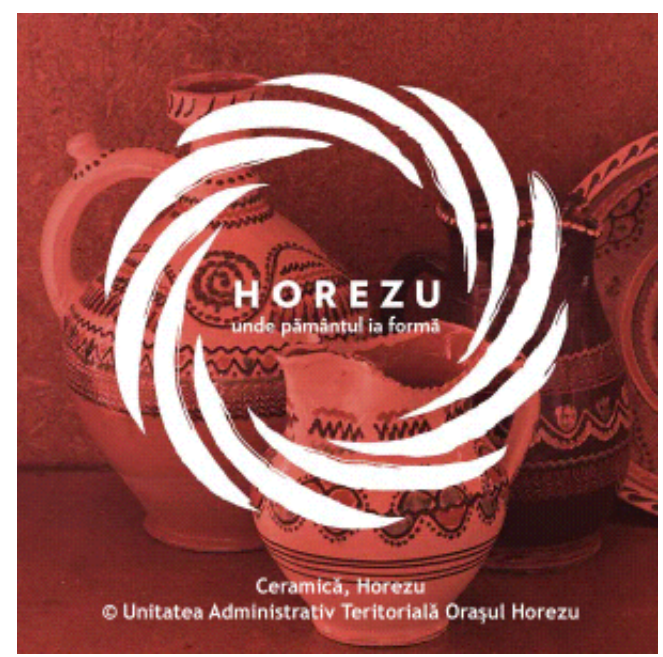

Figure 10. Logo of the campaign 


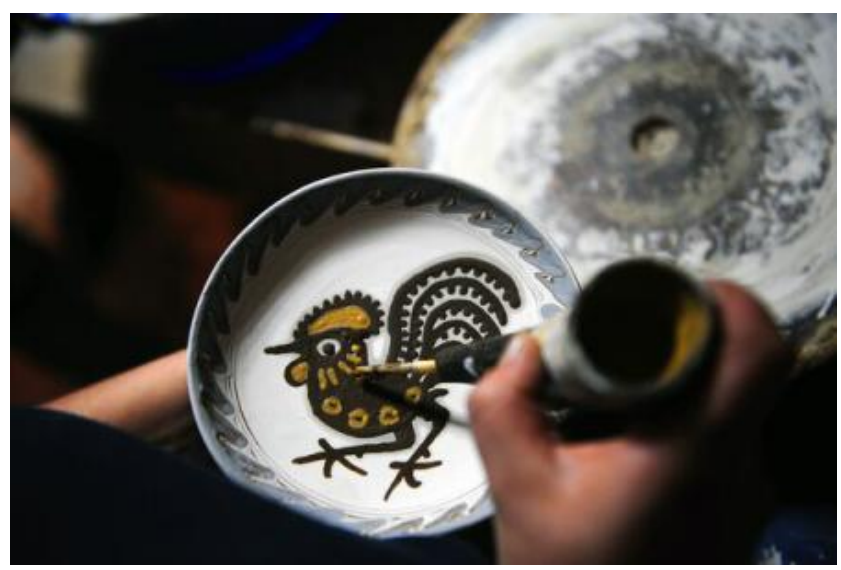

Figure 11. Decorating the plates using traditional "Horezu - where the earth takes shape" techniques and materials

\subsection{Local Community}

Local initiatives were started with the allocation of European funding for implementing social development projects in the mountainous and hilly areas of Romania. As an example, the - "Horezu Region Fair - pleasure of living" was held from June the 29th to July the 1st 2012, funded by Human Resources Development Operational Programme 2007-2013," Invest in people ".

Also, in 2012, the project "Look at Horezu" was implemented. By this project the local administration collaborated with other associations like the CIMEC Institute for Cultural Memory, Arhitext Design Foundation, Atlantic Association - France, as well as the local community represented by TinEcoArt Association and Kogayon Association that provided cultural information and training programs, initiating and carrying out artistic activities.

This project aimed to stimulate the recognition of the existing heritage as a contribution to the local development for younger generations. Through interaction with the project team and through art education activities, the residents of the Horezu region discovered local values and resources that they formally passed over indifferently and learned to appreciate and protect them. Following this project, meetings and exhibitions were conducted and also a brochure was published that summarized all the existing Horezu heritage sites, allowing a more cohesive approach to the promotion of the area with its specific elements.

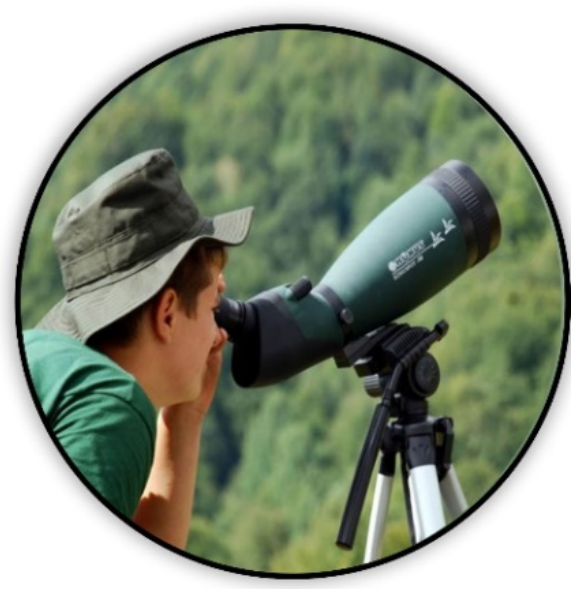

Figure 12. Activities undertaken by the Kogayon Association in the Buila Vanturarita Natural Park with teenagers from the Horezu region

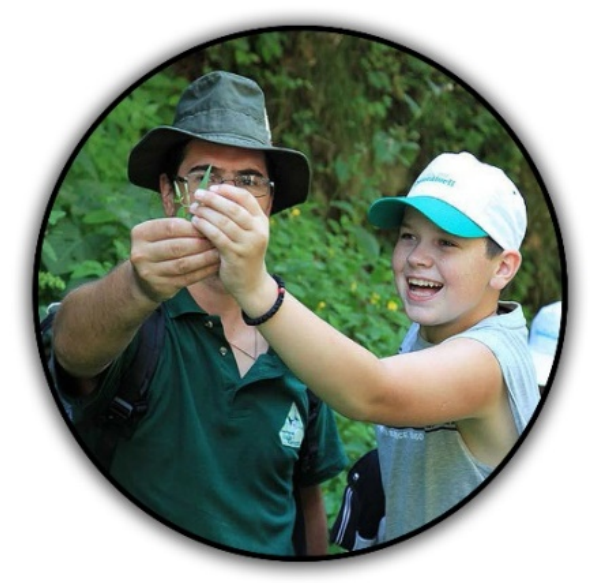

Figure 13. Activities undertaken by the Kogayon Association in the Buila Vanturarita Natural Park with teenagers from the Horezu region

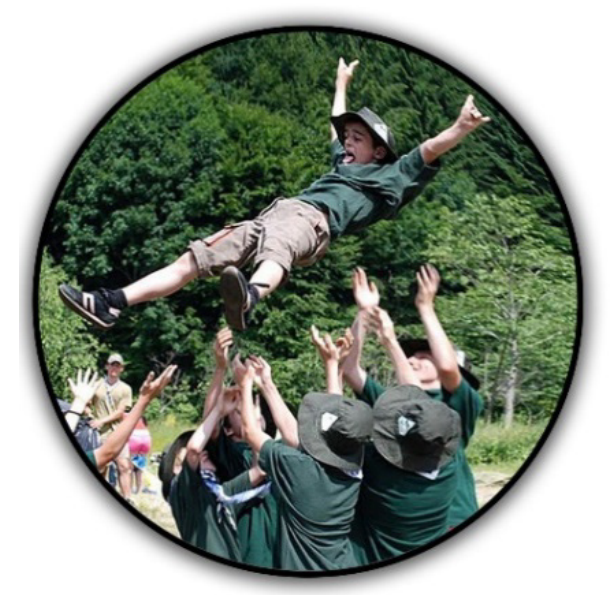

Figure 14. Activities undertaken by the Kogayon Association in the Buila Vanturarita Natural Park with teenagers from the Horezu region 


\subsection{Ecotourism}

In 2005, the city of Horezu becomes a tourist resort of local importance, and in 2008 the European Commission, through the EDEN project, assigns to the Horezu region the title of "European Destination of Excellence", inducing a new stage for the development of the town according to its touristic status.

Even though the number of tourists in the area has increased in the last years, the economic benefits are still scarce as the variety of attractions isn't sufficiently promoted, while the quality of the services is unsatisfying.

The current activities exploit spontaneously and intuitively the advantages of position, environment and natural resources of the area, yet lacking the necessary efficiency to adapt to contemporary conditions. The local economic development is currently dependent on the vitality of the new private sector, as part of the tendencies towards an economy based on offering services. Through ecotourism, the spectrum of traditional economic activities can be ensured instead of being marginalized or replaced. Recent initiatives are encouraged by granting European funding for bioproducts, by establishing small factories that produce local goods or by providing accommodation in traditional households. Thus, the local economy is not subordinated to external changes and influences.

Touristic activities conducted under the title of ecotourism offer specific opportunities to appreciate the valuable natural and cultural objectives. The local population and the tourism industry are forced to use natural resources in a sustainable manner. Only a coherent discourse is able to support ecotourism in the area through the provision of infrastructure, service development, and the organization of thematic routes that can include both the natural environment - the Buila Vanturarita Natural Park, the local customs and traditions the Horezu ceramics, and the built environment - the Horezu Monastery. These measures can ensure a wider range of tourists and a longer visit, opening a more satisfying touristic market.

\section{Conclusions}

The Horezu Pottery and the Horezu Monastery Horezu are emblematic elements that represent the region, ensuring a specific identity. The perpetuation of the pottery craft also suggests the residents initiative of maintaining a cultural core often suppressed during the communist regime.

The 2 objectives included in the UNESCO heritage list expresses the international recognition and the need to undertake measures to maintain these values during the contemporary difficult transition period. For creating a coherent and sustainable strategy, the entire region has to become more attractive, thus solving the existing social problems.

By pointing out these two special components of the cultural landscape, the region's population can be identified with a specific character, which is actually a first step in establishing an administrative cooperation and more community involvement. All these initial endeavors are primarily intended to educate and train the residents, as to easily adapt to the administrative changes implemented nationwide.

Ecotourism may constitute in this sense a variant of gaining independent economic support for the region. Acknowledging all the varied qualities of the Horezu region, one can broaden the touristic range of offers and have the ability to disseminate information among more potential visitors. One of the main target groups are children, they are offered the chance to experience a complete educational program by organizing pottery workshops, hiking and site seeing, while adults have the possibility to be connected to a traditional way of life.

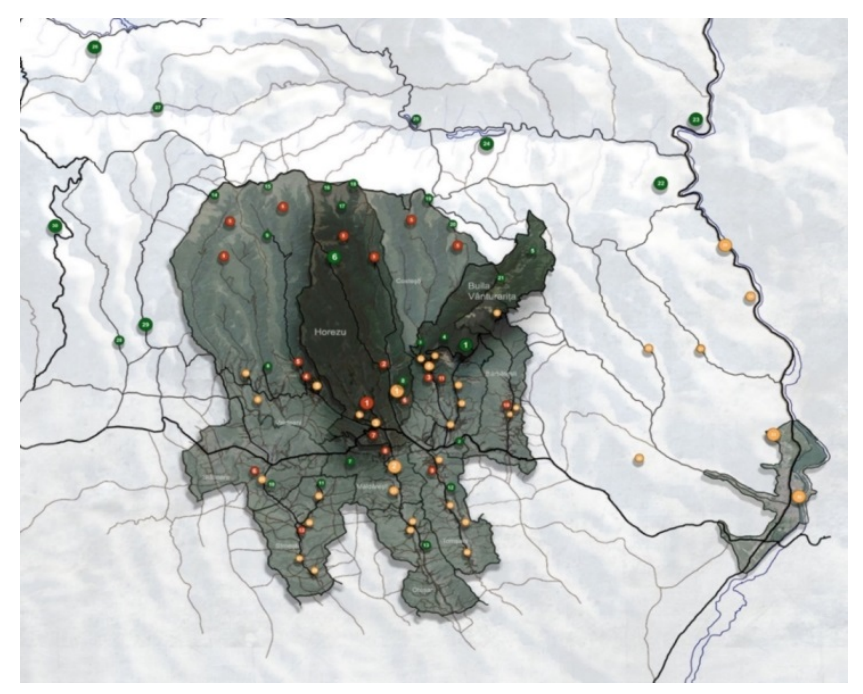

Figure 15. Map showing more than 35 objectives concerning the cultural landscape of Horezu

\section{REFERENCES}

[1] Mihaescu, Corina, 2005, "Ceramica de Horezu", "Contrast" Publishing, Bucharest;

[2] Ciocan Valentin, Ciocan Vetuta, 2012, "Istoria Horezului", "Univers" Publishing, Rm. Valcea, Romania;

[3] Kogayon Association, 2012, "Planul de management al Parcului National Buila Vanturarita", "Univers" Publishing, Rm. Valcea, Romania;

[4] Sporis, Mihai, 2015, "Oltenia de sub munte.Repere Valcene vechi si noi”, “Adrianso” Publishing, Rm. Valcea, Romania;

[5] Panoiu, Andrei, 1982, "Arhitectura traditionala din zona centrala a Gorjului", 1982, Collection: Ansambluri istorice arhitecturale, "Bucuresti" Publishing, Bucharest;

[6] Gheorghiu, Teodor, 2010, "Locuire si neAsezare", "Paideia" Publishing, Bucharest; 
[7] Duculescu, Mirela, 2010 "G.M. Cantacuzino (1899-1960). Arhitectura ca tema a gandirii", Simetria Publishing, Bucharest.

[8] Figures 1, 15: Illustrations made by the authors of this study, 2015;

[9] Figures 2, 3: Local Potters Association of Horezu, 2013;

${ }^{\mathrm{i}}$ The study was conducted for academic purposes. The questionnaire was submitted to a number of 135 subjects with proportional allocation of respondents by age and gender, with a theoretical margin of error of $+/-5 \%$.
[10] Figures 4, 5, 6, 11: Vicsoreanu family, craftesmen in Horezu, 2009;

[11] Figures 7, 8, 12, 13, 14: Kogayon Association, 2012;

[12] Figure 10: Horezu local administration, 2012. 